\title{
DÜBLIN
}

Technological University Dublin

ARROW@TU Dublin

\section{Impact of atmospheric pressure nonequilibrium plasma discharge on polymer surface metrology}

\author{
Laurence Scally \\ Technological University Dublin, laurence.scally@tudublin.ie \\ James Lalor \\ Technological University Dublin, james.lalor@tudublin.ie \\ Patrick J. Cullen \\ Technological University Dublin, patrick.j.cullen@tudublin.ie
}

See next page for additional authors

Follow this and additional works at: https://arrow.tudublin.ie/schfsehart

Part of the Environmental Chemistry Commons, Environmental Health Commons, Environmental Sciences Commons, and the Medicine and Health Sciences Commons

\section{Recommended Citation}

J. Vac. Sci. Technol. A 35, $03 E 105$ (2017); DOI: 10.1116/1.4978254

This Article is brought to you for free and open access by the School of Food Science and Environmental Health at ARROW@TU Dublin. It has been accepted for inclusion in Articles by an authorized administrator of ARROW@TU Dublin. For more information, please contact arrow.admin@tudublin.ie, aisling.coyne@tudublin.ie, gerard.connolly@tudublin.ie.

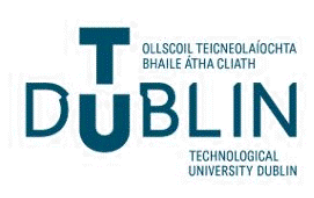




\section{Authors}

Laurence Scally, James Lalor, Patrick J. Cullen, and Vladimir Milosavljevic 


\section{Impact of atmospheric pressure nonequilibrium plasma discharge on polymer surface metrology}

Cite as: J. Vac. Sci. Technol. A 35, 03 E105 (2017); https://doi.org/10.1116/1.4978254

Submitted: 01 November 2016 • Accepted: 22 February 2017 • Published Online: 13 March 2017

Laurence Scally, James Lalor, Patrick J. Cullen, et al.
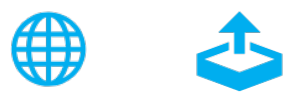

\section{ARTICLES YOU MAY BE INTERESTED IN}

Effect of water vapor on plasma processing at atmospheric pressure: Polymer etching and surface modification by an $\mathrm{Ar} / \mathrm{H}_{2} \mathrm{O}$ plasma jet

Journal of Vacuum Science \& Technology A 37, 031305 (2019); https://

doi.org/10.1116/1.5092272

$\mathrm{O}^{\circ}, \mathrm{H}^{\circ}$, and ${ }^{\circ} \mathrm{OH}$ radical etching probability of polystyrene obtained for a radio frequency driven atmospheric pressure plasma jet

Journal of Vacuum Science \& Technology A 38, 033012 (2020); https://

doi.org/10.1116/6.0000123

Plasma-surface interaction at atmospheric pressure: A case study of polystyrene etching and surface modification by $\mathrm{Ar} / \mathrm{O}_{2}$ plasma jet

Journal of Vacuum Science \& Technology A 35, 05 C315 (2017); https://

doi.org/10.1116/1.5000691

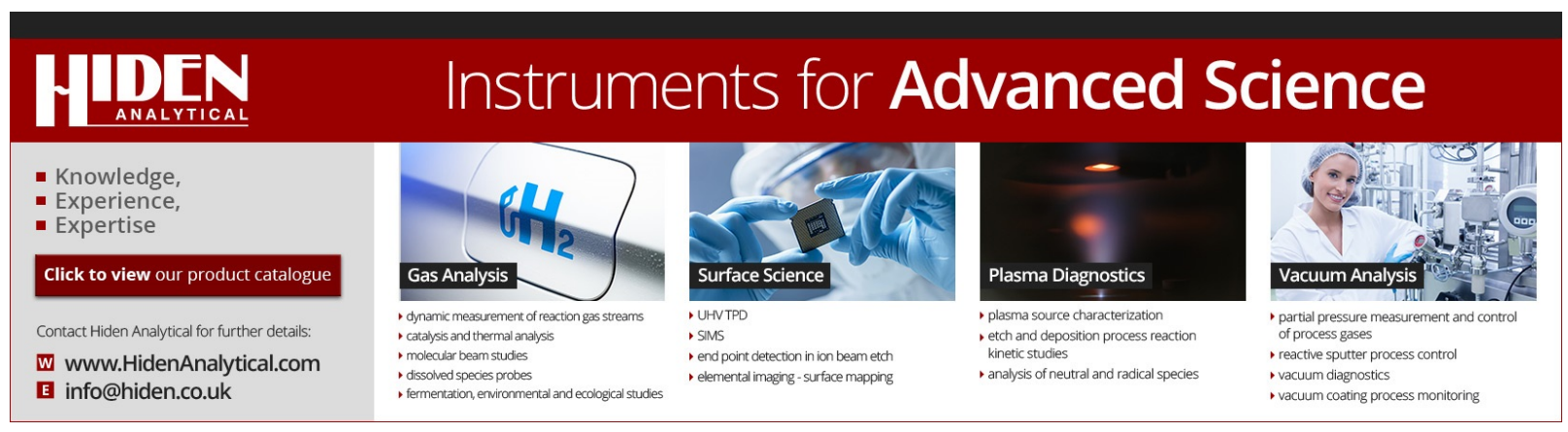




\title{
Impact of atmospheric pressure nonequilibrium plasma discharge on polymer surface metrology
}

\author{
Laurence Scally \\ BioPlasma Research Group, Dublin Institute of Technology, Sackville Place, Dublin 1, Ireland \\ James Lalor \\ BioPlasma Research Group, Dublin Institute of Technology, Sackville Place, Dublin 1, Ireland and School \\ of Applied Technology, Dublin Institute of Technology, Bolton Street, Dublin 1, Ireland \\ Patrick J. Cullen \\ BioPlasma Research Group, Dublin Institute of Technology, Sackville Place, Dublin 1, Ireland and School \\ of Chemical Engineering, UNSW, Sydney, New South Wales 2052, Australia \\ Vladimir Milosavljevića) \\ BioPlasma Research Group, Dublin Institute of Technology, Sackville Place, Dublin 1, Ireland and Faculty \\ of Physics, University of Belgrade, P.O.B. 368, Belgrade 11000, Serbia
}

(Received 1 November 2016; accepted 22 February 2017; published 13 March 2017)

\begin{abstract}
Due to the attraction of plasma technologies as a clean and efficient means of surface modification, significant research has gone into the physical and chemical aspects of polymer functionalization. In this study, it was shown that the use of an atmospheric plasma jet can efficiently modify the surface of polyethylene terephthalate samples and change their hydrophobic properties to more hydrophilic characteristics. The dependence on the changes with respect to time, distance, and atomic oxygen (O I) intensity were considered as factors. It was found that with closer proximity to the plasma source (without causing thermal degradation) and with increasing levels of O I, that the changes of water contact angle and surface free energy can be maximized. It was also observed that the electron energy distribution function, for a given chemistry, significantly differed with changes in distance from the jet nozzle. This shows that for this type of plasma jet system, the bulk of the chemical reactions occur in the nozzle of the jet and not in the surrounding atmosphere. Therefore, this leads to more efficient energy transfer, higher gas temperatures, and better surface activation of samples when compared to systems that produce external chemical reactions due to more diffusion in the surrounding atmosphere and loss of reactive species to other atoms and molecules that are present. (C) 2017 American Vacuum Society. [http://dx.doi.org/10.1116/1.4978254]
\end{abstract}

\section{INTRODUCTION}

The use of polymers continues to replace traditional materials such as glass and paper for numerous processing industries. The modification and functionalization of different polymers has been effectively achieved through the use of nonthermal plasma-surface interactions. By introducing the surfaces of various materials to the reactive species, high energy electrons, and ion bombardments associated with plasma discharges, a variety of interactions occur. An effect of using high energy electrons, atoms, and molecules on the surface of polymer materials such as polyethylene or polyethylene terephthalate (PET) is that surfaces can be modified to become more polar, and as a result, they become more hydrophilic and have their surface energies increased..$^{1-3}$ This can cause surfaces to become more reactive and accepting of solutions introduced to the surface. ${ }^{4}$ Through the use of ion bombardment on the outer layers of a material, atomic crevices can be created, which then become small binding pockets, which allow for better adhesion between plastic packaging during heat sealing of containers. ${ }^{5,6}$ The combination of these different aspects allows for packaging films that can be

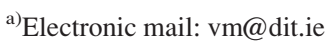

sterilized, can create further reactions with the packaged samples that may increase product shelf life, create a stronger packaging seal, and impart antimicrobial properties. ${ }^{7}$

Advantages of nonthermal plasma include reduced temperature treatment of samples, such as autoclaving, creating a more convenient method of sterilization and the ability to strengthen or functionalize materials. This allows for a wider range of samples to be treated, which is important for materials such as thin layer films for packaging as these are typically sensitive to thermal degradation. Current nonthermal plasma systems include plasma jets, dielectric barrier discharge, and corona discharge systems with applications including medical, food, and material processing. ${ }^{8}$ The use of plasma treatment systems in these fields shows that there is an importance to intimately understand and predict the phenomena that take place at the surface boundaries of the treated materials. With material processing, nonthermal plasma can be used to make a plastic polymer more hydrophilic and create more binding sites for stronger adhesion for product packaging. By introducing the polymer samples to ambient atmospheric plasma discharges, the surface may undergo reactive mechanisms that create a more polar surface, allowing for better acceptance of water molecules. Various plastic polymers have been studied for the use in a 
large range of areas such as food packaging, electrical, and biomedical industries. ${ }^{9,10}$ Since polymers can be thermally damaged relatively easily, precautions are needed during the treatment of these materials as their integrity can be diminished quickly if exposed to the plume of a plasma jet.

For the various methods that nonthermal plasmas are employed to modify different material surfaces, it is a necessity to be able to determine what and to what degree an effect occurs. Oxygen containing gases have been reported to play an important role in the modification of polymer surfaces, inducing greater effects when compared to inert gases such as argon (Ar). ${ }^{11-14}$ This is due to gases having an oxygen content being able to etch and activate surfaces, modifying carbon-oxygen bonds to create different functional groups and therefore different surface properties. ${ }^{15}$ In order to carry out the investigation described in this work, the use of water contact angle (WCA) and surface free energy (SFE) measurements was employed to determine how much surface modification and activation occurred after nonthermal plasma treatment. To compare the effects of treatment time, sample distance, and gases used, optical emission spectroscopy (OES) measurements were carried out to identify and analyze the intensities of atomic oxygen spectral lines generated by the plasma discharge, as well as spectral emissions of other species from the plasma. Second, OES was employed to identify optimum plasma treatment conditions for PET surface modification, where the electron energy distribution function (EEDF) was calculated for Ar gas chemistry to show shifts in the energies of electrons. Such energy shifts would indicate at which points the optimum transfer of energy and chemical reactions for functionalization occur. These parameters were then used to create an experimental study for the determination of an online analysis of the surface metrology of plasma treated PET samples.

Air was chosen as one of the inducer gases as it is economically and environmentally friendly and is typically involved in open air reactions when other gases are employed. This provides a good baseline for determining, with a higher degree of certainty, what effects occur with changes in gas properties and how this relates to gas chemistry interactions. $\mathrm{CO}_{2}$ was chosen due to its frequent use in the food industry. Helium $(\mathrm{He})$ is a recommended gas for the PVA plasma jet system used. We also employed argon (Ar) in this study as it has similar properties to He. As both of these gases have an inert nature, they can be used to compare the gas chemistry of the other two gases and study how they would further react with the atmosphere surrounding the nozzle influencing the creation of the reactive species. This allows a comparison between each gas to be made and identification of which species (in this case, atomic oxygen) can be related back to the changes in WCA and SFE and how the chemical reactions develop over time and distance. PET is one of the most commonly used polymers for packaging. Insights into the possible secondary effects of nonthermal plasma treated samples can have on the PET film they are sealed with, and vice versa, are needed to identify what, if any, long-term benefits or problems may occur.

\section{EXPERIMENT}

\section{A. Setup}

Experimental treatments of PET were carried out using the PlasmaPen ${ }^{\mathrm{TM}}$, which is manufactured by PVA TePla and can be seen in Fig. 1. The system operates at a gas pressure of $600 \mathrm{kPa}$ for mixtures of gases including $\mathrm{N}_{2}, \mathrm{~N}_{2} / \mathrm{H}_{2}, \mathrm{O}_{2}$, and $\mathrm{CO}_{2}$. The system allows for a maximum gas flow of about $22 \mathrm{l} / \mathrm{min}$. The frequency at which the plasma is generated is $60 \mathrm{~Hz}$, creating an environment where the oscillation of electrons and heavy particles, such as ions, can occur. The diagnostics of the plasma are limited to optical spectroscopy techniques due to the plasma generator and its matching network being housed in a closed off case. An air compressor was used to generate air flow through the system so that there was a continuous gas flow out of the nozzle of the plasma jet. Apart from the compressed air, cylinders of high purity $\mathrm{CO}_{2}$, Ar, and $\mathrm{He}$ were used. The gas flow (from the air compressor $/ \mathrm{CO}_{2} / \mathrm{Ar} / \mathrm{He}$ ) causes the plasma to be pushed out of the plasma pen in a narrow stream and allows for greater targeting of samples. There is no control over the gas flow once the pressure has been set on the air compressor or gas cylinders used to supply the atmospheric plasma jet. The position of the jet was controlled with a robotic arm along the $\mathrm{x}-, \mathrm{y}-$, and $\mathrm{z}$-axes through the use of a computer numeric control (CNC) software. This allowed for high precision movement, which was a necessity to determine the minimum distance at which the treatment of PET could be operated without inducing thermal damage.

\section{B. Polymer treatment}

The treatment of the samples was carried out in triplicate to obtain an average and to note any variances occurring during the treatment process. In total, nine batches of PET were treated. Each batch consisted of samples that were treated at four different times, and this was done three times or each sample, giving 12 samples per batch. The treatment times for these four different samples were 5, 10, 20, and $40 \mathrm{~s}$. The same times were used throughout the different batches, but the distance from the plasma source was increased by $5 \mathrm{~mm}$ from batch 1 to batch 2 and from batch 2 to batch 3. Before

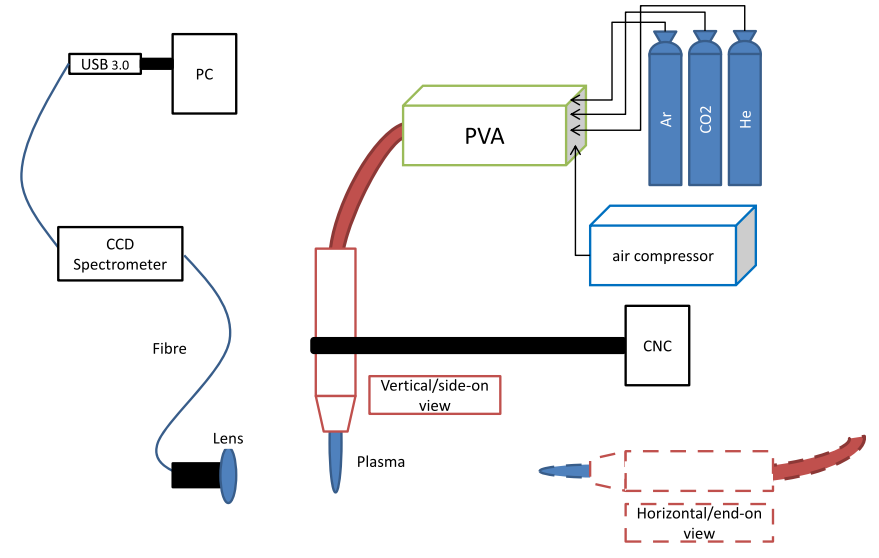

FIG. 1. (Color online) Schematic of plasma system setup and references of orientations used for OES acquisition. 
the plasma was ignited, each gas was allowed to run through the system to flush out any contaminants. Before taking optical emission spectroscopy measurements and before the treatment of any samples, the power was turned on to the system to allow for a short period of ignition before then turning it off again to prepare the samples on the treatment stage under the jet.

\section{Optical emission spectroscopy}

In order to gather the required OES measurements, an Edmund Optics CCD spectrometer was used. This device has a spectral resolution of $1.5 \mathrm{~nm}$ and can record emissions between 200 and $850 \mathrm{~nm}$. Due to the spectral resolution associated with this spectrometer, some emission peaks may overlap. For example, the three emission peaks of the atomic oxygen triplet at the $777 \mathrm{~nm}$ mark are too close for this device to separate as individual peaks and consequently display as a singular, broader emission peak. ${ }^{16}$ The software used to record and analyze the data was BWSpec ${ }^{\mathrm{TM}}$. We have used a single fiber optic cable with a lens and a CNC machine. The optical emission spectroscopy studies were conducted by moving the jet along the z-axis (of the CNC machine) relative to the fiber optic lens. The zero point was taken as being at the jet nozzle with the jet moving farther up the z-axis and the lens then taking readings further down the plasma plume. In this study, it was deemed that the common active species between all three gases was atomic oxygen (O I). This is of particular interest as it has been found to cause modifications of polymer surfaces. In other studies, it has been shown that gases containing oxygen species cause a dual effect of etching and modifying bonds on polymer surfaces.

\section{WCA and SFE measurement apparatus}

Theta Lite from Biolin Scientific was used in order to carry out the WCA and SFE measurements on the PET samples. The sessile drop technique is used with this system and over the course of $10 \mathrm{~s}$ data are recorded, giving the angles on both sides of the drop on a surface and their associated standard deviations. The angles that are given from the WCA measurement can then be averaged and then chosen to calculate the average surface free energy of a sample. The software which is used to run these diagnostic measurements Was ONEATTENSION.

\section{RESULTS AND DISCUSSION}

Plasma diagnostics for each gas were performed using OES measurements. A comparison of the different emission spectra can be seen in Fig. 2. In order to show the differences between the emissions for each gas, background emissions have been taken into account. Of particular interest is the ability of the approach to differentiate between the three gases and their effects on the surface of the PET samples. In order to do this, the emissions of atomic oxygen $(\mathrm{O} I)$ were identified for each gas and a comparison of the different intensities was made for O I. Atomic oxygen was chosen as it has been reported that the etch rate of polymer surfaces

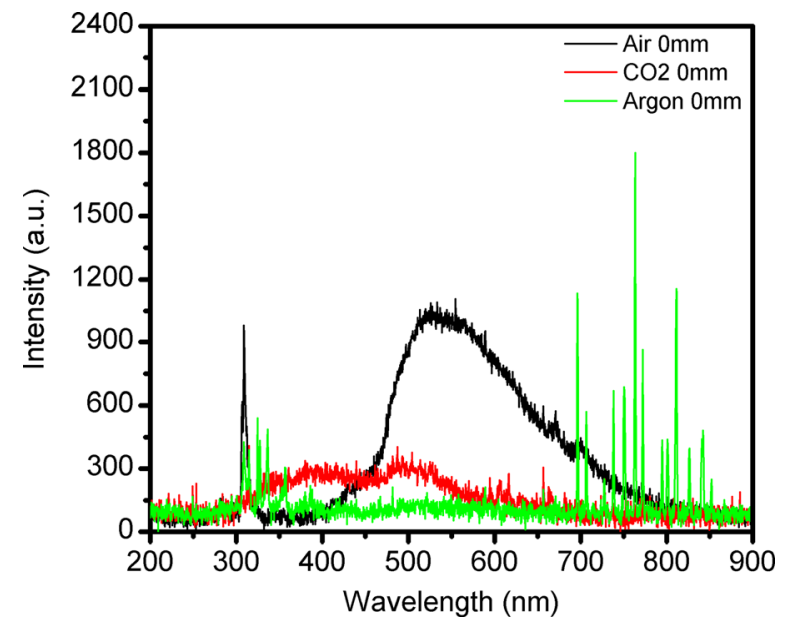

FIG. 2. (Color online) Typical spectral emissions of nonthermal atmospheric pressure plasma discharge for carrier gases: air, $\mathrm{Ar}$, and $\mathrm{CO}_{2}$.

through the use of a plasma containing oxygen has two effects: (1) etching of the surface of the polymer due to reactions of the oxygen atoms with carbon atoms on the surface and (2) the creation of oxygen rich functional groups on the polymer surface due to reactions between reactive species in the plasma and the surface atoms. The oxygen functional groups that the plasma can react with at the polymer surface include $\mathrm{C}-\mathrm{O}, \mathrm{C}=\mathrm{O}, \mathrm{O}-\mathrm{C}=\mathrm{O}, \mathrm{C}-\mathrm{O}-\mathrm{O}$, and $\mathrm{CO}_{3} .{ }^{17}$ In the case of PET, the interaction of plasma with the surface leads to the $-\mathrm{C}-\mathrm{O}-$ bond breaking in ester groups, which causes a disruption in the polymer chain, and allows for a higher level of polarity on the surface. ${ }^{18}$ However, measurements on the changes of surface roughness were not conducted directly, but the changes of the water contact angle gave an insight into the changes that occurred due to plasma chemistry interactions with the surface. ${ }^{19}$ Due to a decreased water contact angle it is clear that the surface roughness and polarity would have increased after treatment. Table I shows the emission of $\mathrm{O}$ I for each gas and their associated data.

Figure 2 shows a broad continuum in the range of $400-820 \mathrm{~nm}$ for air and a continuum in the range of 300-700 nm for $\mathrm{CO}_{2}$. The continuum for air represents an emission of $\mathrm{NO}_{2}{ }^{*}$. The continuum, or swan band, in $\mathrm{CO}_{2}$ is due to the emission of $\mathrm{CO}$ and $\mathrm{C}_{2}$.

\section{A. Polymer treatment with air}

The mechanism for the production of the $\mathrm{NO}_{2}{ }^{*}$ continuum has been reported to be due to the recombination of $\mathrm{NO}$ $+\mathrm{O}$, given by the following reaction mechanisms, where $\mathrm{M}$ is a third body molecule, such as $\mathrm{O}_{2}, \mathrm{O}_{3}$, or $\mathrm{N}_{2}^{21-23}$

$$
\begin{aligned}
& \mathrm{NO}+\mathrm{O} \rightleftharpoons\left[\mathrm{NO}_{2}{ }^{*}\right] \\
& \mathrm{N}_{2}(\mathrm{v})+\mathrm{O} \rightleftharpoons \mathrm{NO}+\mathrm{N}, \\
& {\left[\mathrm{NO}_{2}{ }^{*}\right]+\mathrm{M} \rightarrow \mathrm{NO}_{2}{ }^{*}+\mathrm{M},} \\
& {\left[\mathrm{NO}_{2}{ }^{*}\right] \rightarrow \mathrm{NO}_{2}+h v,} \\
& \mathrm{NO}+\mathrm{HO}_{2} \rightarrow \mathrm{NO}_{2}+\mathrm{OH} .
\end{aligned}
$$


TABLE I. Spectroscopic data for atomic oxygen (O I) for each gas used. The transitions, multiplets, transition probabilities $(A)$, and initial and final energy levels ( $E_{i}$ and $E_{f}$ ) were gathered from the NIST database (Ref. 20).

\begin{tabular}{lcclccc}
\hline \hline & & & & \\
Emitter & Transition & Multiplet & $(1 / \mathrm{s})$ & $E_{i}$ & $E_{f}$ \\
\cline { 5 - 7 } & & & $(\mathrm{eV})$ & $(\mathrm{eV})$ \\
$\mathrm{O}_{615}$ & $3 p-4 d$ & ${ }^{5} \mathrm{P}_{3}-{ }^{5} \mathrm{D}^{0}{ }_{4}$ & $5.72 \times 10^{6}$ & 12.7536965 & 10.740931 \\
$\mathrm{O}_{777}$ & $3 p-3 s$ & ${ }^{5} \mathrm{~S}^{0}{ }_{2-}{ }^{5} \mathrm{P}_{1}$ & $3.69 \times 10^{7}$ & 10.740224 & 9.140906 \\
$\mathrm{O}_{845}$ & $3 p-3 s$ & ${ }^{3} \mathrm{~S}^{0}{ }_{1-}{ }^{3} \mathrm{P}_{0}$ & $3.22 \times 10^{7}$ & 10.988880 & 9.5213632 \\
\hline \hline
\end{tabular}

As can be seen in Fig. 2, the emission of NO is relatively low, and there are no visible emission peaks for $\mathrm{N}_{2}$ where one would expect to see the second positive band. This lends precedence to the idea that the $\mathrm{N}_{2}$ molecule interacts with other species, in this case $\mathrm{O}$, and has a vibrational transfer of energy that creates NO molecules. These NO molecules can then be further oxidized and gain energy from a third body $\mathrm{M}$ to create $\mathrm{NO}_{2}{ }^{*}$, which then emits in the wavelength range observed.

The air that is represented in Fig. 3 was delivered to the PVA system using an air compressor. This compressor took the ambient air of the room and directed it to the plasma jet through which then generated plasma as the air flowed through at a pressure of 6 bars. In Fig. 3(a), it can be seen that the total intensities of $\mathrm{O}$ I emissions in air tend to be higher on average at a distance of around $2-4 \mathrm{~mm}$ from the nozzle. From this, it can be seen that there is a dependence on the intensity and quantity of the reactive species with respect to distance. Consequently, the closer the sample is to the source the more interaction the surface will have with the produced $\mathrm{O}$ I atoms. There is also a degradation over time of the $\mathrm{O} I$ atoms at $0 \mathrm{~mm}$, which indicates that there could be reactions occurring that reduce the reactive $\mathrm{O}$ I species over time. However, there is an increase of $\mathrm{O} I$ at 2 and $4 \mathrm{~mm}$ and then a decrease with an increase in distance; this shows that there is a recombination process occurring, which is shown in reaction mechanisms (1 and 2). The high levels of $\mathrm{OH}$ at the beginning of the measurements when using air as the gas for plasma discharge can be associated with the high humidity present as the gas is passed through the jet from the air compressor. The intensities of $\mathrm{OH}$ and $\mathrm{NO}_{2}{ }^{*}$ are highest at $0 \mathrm{~mm}$ and in the first few seconds of plasma generation. There is then degradation over time and with respect to distance. However, as can be seen in Figs. 3(b) and 3(c), the intensities of these do drop with an increase in distance, but also give a more consistent emission at points further away from the nozzle. This indicates that the main reactions that occur are within $0-2 \mathrm{~mm}$ of the nozzle and allow for a more continuous flow of reactive species further away from the nozzle due to less reactions occurring within the gas.

Figure 4 shows that distance plays a significant role in the treatment of the polymer surface. This is in line with the OES data, which shows a decrease in O I emissions with increasing distance from the plasma source. The closer the sample is to the source the more interactions it can have with the reactive oxygen species which modify the surface to become more polar and hence more hydrophilic, decreasing
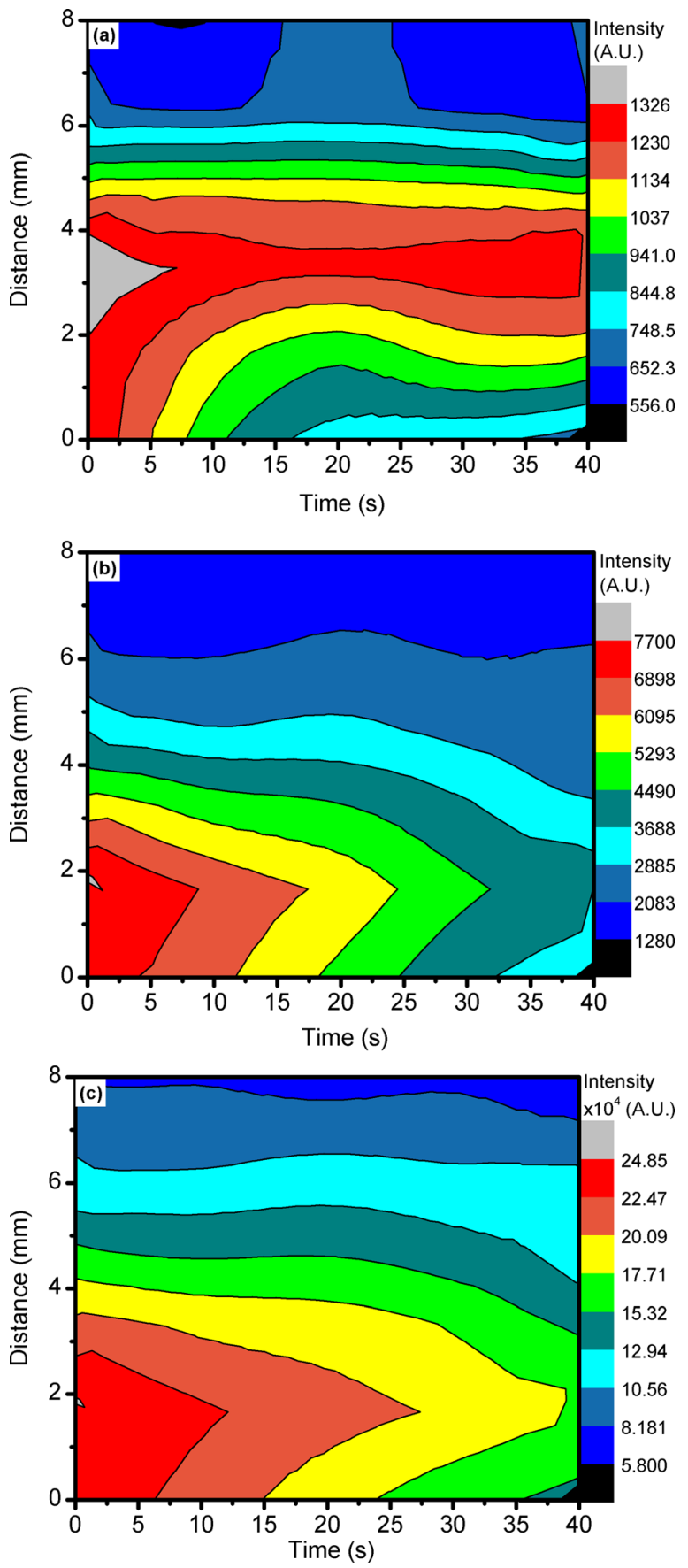

FIG. 3. (Color online) (a) Comparison of O I emissions in air over time and distances from the plasma jet nozzle. (b) Comparison of $\mathrm{OH}$ emission intensities over time and distance. (c) Comparison of the $\mathrm{NO}_{2}{ }^{*}$ continuum over time and distance.

the WCA and increasing the SFE. The increase in the SFE can be seen in Fig. 5 .

\section{B. Polymer treatment with $\mathrm{CO}_{2}$}

The broad $\mathrm{CO}_{2}$ emission bands were found to be swan bands which contain emissions of the $\mathrm{CO}$ third positive system and the Angstrom system and $\mathrm{C}_{2}$ molecules. ${ }^{24}$ As with the emission spectra of air, there does not appear to be any major emission of $\mathrm{N}_{2}$, although it could be that the emission is too low to be detected and has blended in with the 


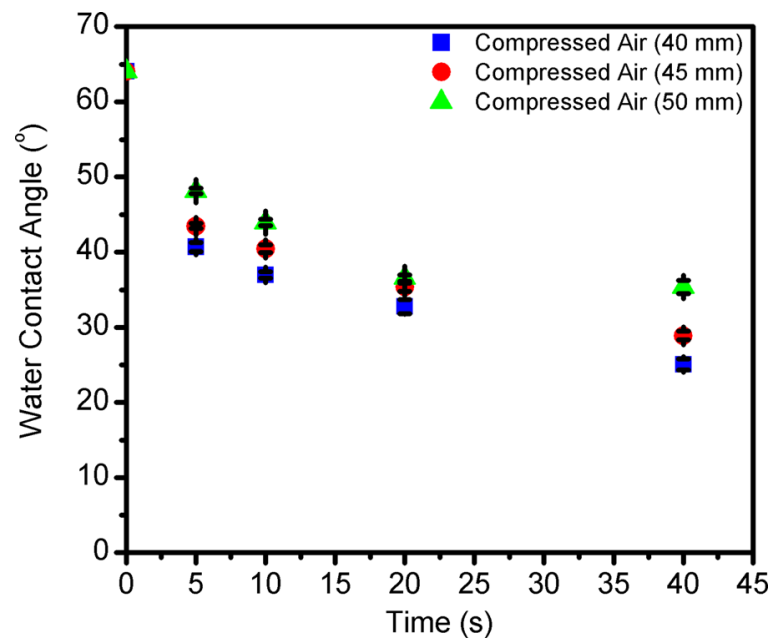

FIG. 4. (Color online) Changes in the WCA with different treatment times at 40,45 , and $50 \mathrm{~mm}$ away from the nozzle tip.

background signal. Although $\mathrm{CO}_{2}$ gas was used, there will be interactions with the surrounding ambient air which will contribute to some of the observed emission and the reaction mechanisms. From this, the mechanism of action for the creation of these swan bands and the emission of $\mathrm{O}_{615}, \mathrm{O}_{777}$, and $\mathrm{O}_{845}$ was found ${ }^{25}$

$$
\begin{aligned}
& \mathrm{CO}_{2} \rightarrow \mathrm{CO}+\frac{1}{2} \mathrm{O}_{2}, \\
& \mathrm{e}+\mathrm{CO}_{2} \rightarrow \mathrm{CO}\left(\mathrm{a}^{3} \Sigma\right)+\mathrm{O}, \\
& \mathrm{e}+\mathrm{CO}_{2} \rightarrow \mathrm{CO}^{+}\left(\mathrm{A}^{2} \Pi\right)+\mathrm{O}, \\
& \mathrm{N}+\mathrm{NO}_{2} \rightarrow 2 \mathrm{NO}, \\
& \mathrm{C}+\mathrm{NO} \rightarrow \mathrm{CO}+\mathrm{N} .
\end{aligned}
$$

As evident from Fig. 6(a), there is a greater drop in the total intensities of the $\mathrm{O}$ I emissions for $\mathrm{CO}_{2}$ at distances further from the nozzle. At $0 \mathrm{~mm}$, there is a greater change in the $\mathrm{O}$ I emission intensities over time, suggesting similar behavior as observed with the air plasma discharge, with

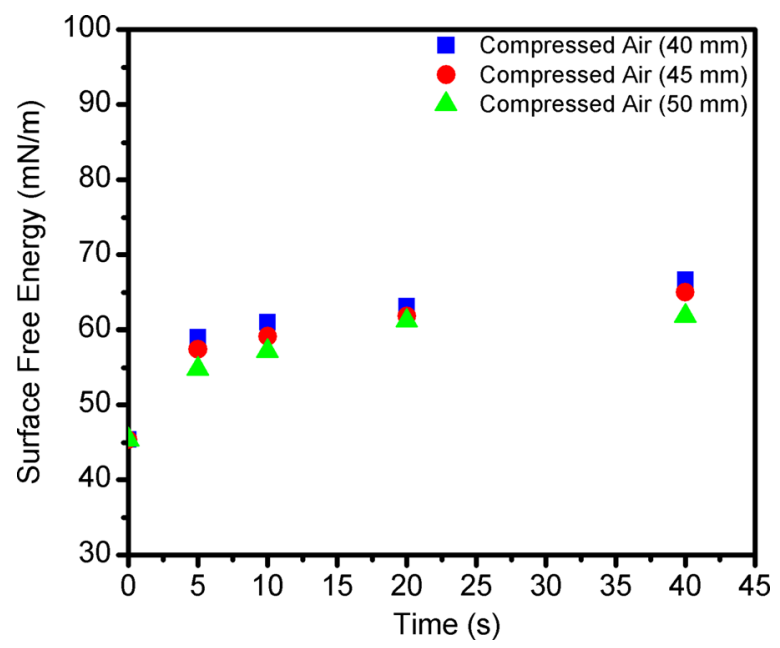

FIG. 5. (Color online) Changes in the SFE with treatment times at 40, 45, and $50 \mathrm{~mm}$ away from the nozzle tip. increased reaction occurring at this point and causing fluctuations in the population of the reactive oxygen species. However, at further points from the nozzle, these appear to stabilize and yield more constant values for the intensities of O I. From Figs. 6(b) and 6(c), it can be seen that the emission of $\mathrm{OH}$ and the overall carbon molecular spectral emissions are greatest at the nozzle and are relatively consistent over time. Moving further away from the nozzle shows that the intensities drop, meaning that most reactions have occurred at the $0 \mathrm{~mm}$ point and as such allow $\mathrm{O}$ I to continue to travel
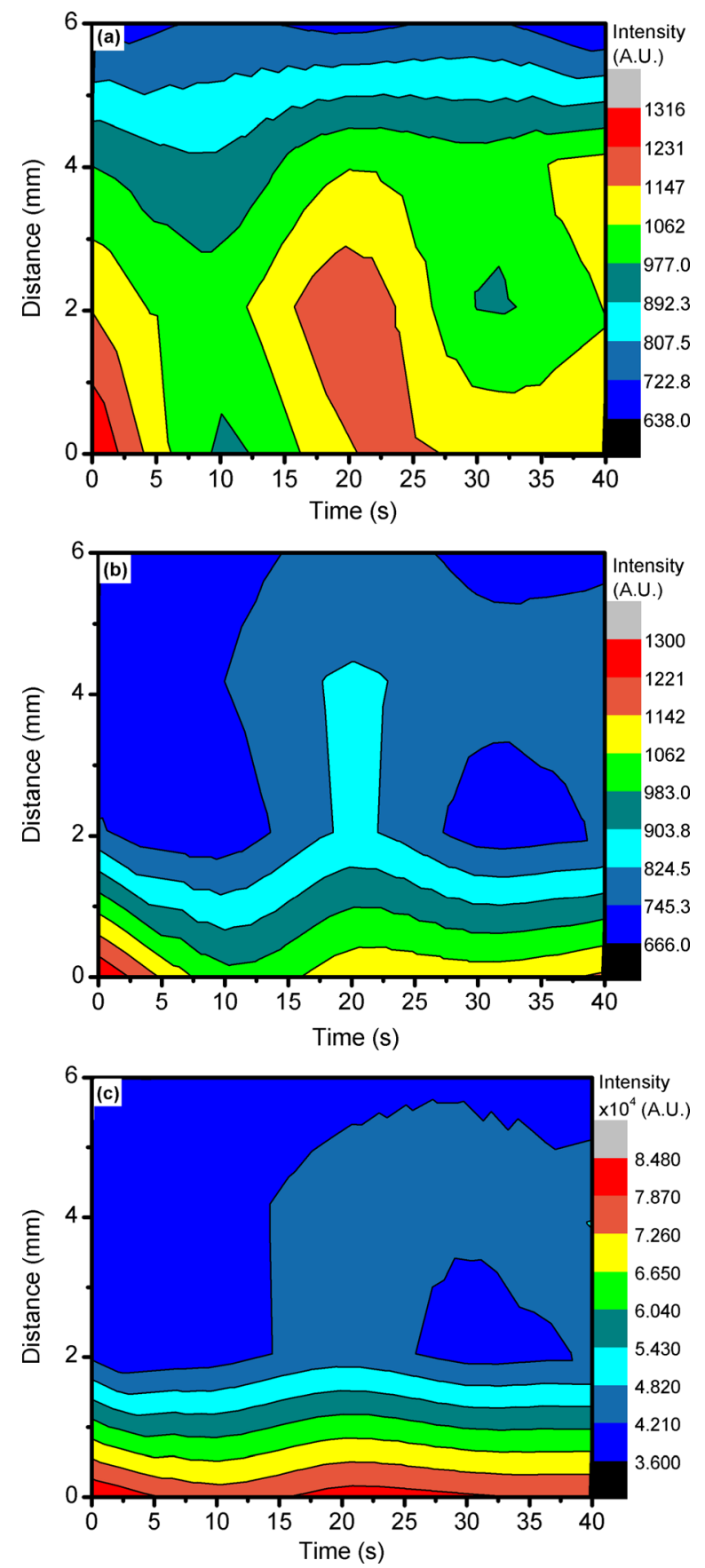

FIG. 6. (Color online) (a) Comparison of O I emissions in $\mathrm{CO}_{2}$ over time and distance from the plasma jet nozzle. (b) Comparison of $\mathrm{OH}$ emission intensities over time and distance. (c) Comparison of the swan band continuum over time and distance. 


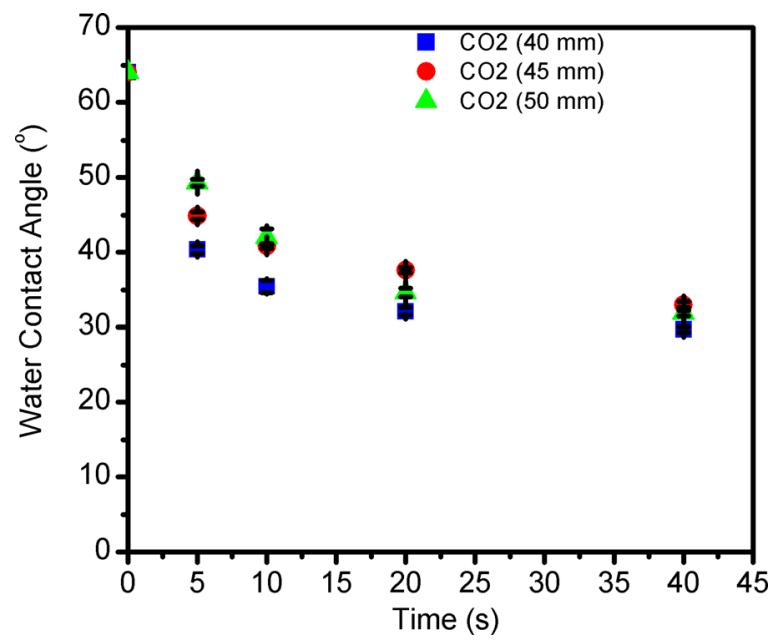

FIG. 7. (Color online) WCA values at varying distances and treatment times with $\mathrm{CO}_{2}$.

over greater distances due to saturation of reactions at the earlier position.

The WCA values in Fig. 7 show there is a dependence on distance for the processing of the PET samples with plasma, but there is also some dependence with time. Although the different distances give varying values throughout the treatment process, the largest differences are observed between 5 and $20 \mathrm{~s}$, with less differentiation at $40 \mathrm{~s}$. This could be due to slight fluctuations of oxygen species over time or the introduction of more $\mathrm{C}-\mathrm{O}$ bonds from other reactions hindering the process of creating a more polar surface and capping the maximum WCA. The SFE changes can be seen in Fig. 8 and correspond to the changes of the WCA.

\section{Polymer treatment with Ar}

Within the argon emission spectrum, it can be seen that there are emissions of $\mathrm{Ar}, \mathrm{O}, \mathrm{OH}$, and the $\mathrm{N}_{2}$ second positive system [Figs. 9(a)-9(f)]. Due to the chemically inert nature of the argon gas, it was determined that there was most likely energy transfer from the metastable atoms (spectral emission at 801 and $810 \mathrm{~nm}$ could be linked to metastable atom density ${ }^{26}$ ), other atomic and molecular species in the ambient air surrounding the plasma jet, and high energy electrons (important for a spectral emission at $750 \mathrm{~nm}$ ), all of which were taken into consideration to aid in the reactions of different species. Reaction mechanisms (11)-(13) show how this could occur ${ }^{27}$

$$
\begin{aligned}
& \mathrm{Ar}+\mathrm{e} \rightarrow \mathrm{Ar}^{*}+\mathrm{e}, \\
& \mathrm{Ar}^{*}+\mathrm{O}_{2} \rightarrow \mathrm{Ar}+2 \mathrm{O}, \\
& \mathrm{Ar}^{*}+\mathrm{N}_{2} \rightleftharpoons \mathrm{Ar}+\mathrm{N}_{2}{ }^{*} .
\end{aligned}
$$

After conducting analysis on the emission spectra of all three of these gases, it was concluded that the common active species of interest between them was O I, and so the intensities of $\mathrm{O}$ I emissions were measured for each at the wavelengths specified in Table I. The intensities were compared in order to determine if a correlation could be derived between the changes in WCA and SFE with respect to

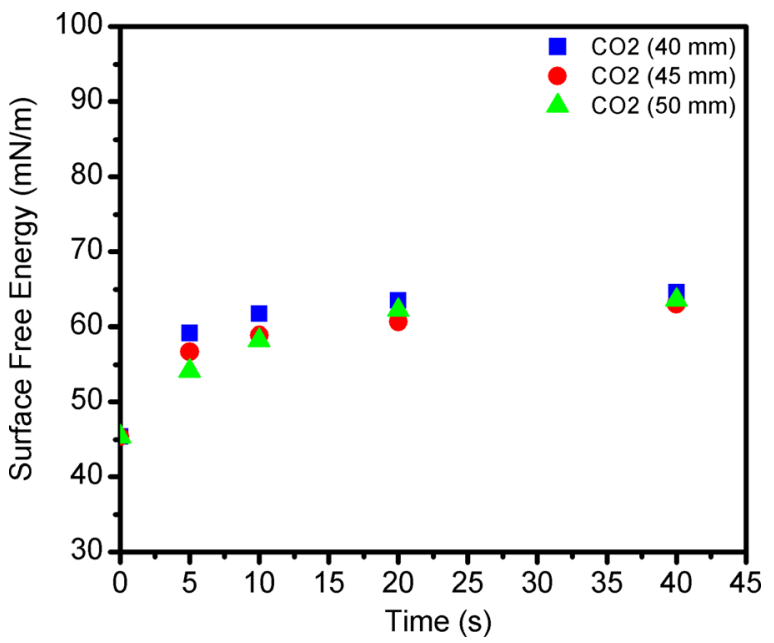

FIG. 8. (Color online) SFE values for PET samples treated with $\mathrm{CO}_{2}$.

changes in $\mathrm{O}$ I emission as these atoms seem to have a larger impact on the modification of polymer surfaces.

From the analysis of the EEDF for the experiment with $\mathrm{Ar}$, it is proposed that the majority of the chemical reactions occur within the plasma jet instead of outside of the nozzle [Fig. 9(g)]. This allows for little change to occur with regards to the efficiency of energy transfer, the degree of activation or the dissipation of reactive species when they leave the jet nozzle. As the chemical reactions occur internally rather than outside of the nozzle, more of the energized species can reach and react with the surface of the sample being treated. For chemically inert noble gases such as $\mathrm{Ar}, \mathrm{He}$, or $\mathrm{Ne}$, there is greater control over directional flow as there are not as many reactions with the ambient air occurring to carry away and diffuse the energetic species being created once they leave the nozzle. However, for many other atmospheric plasma jets, the chemical reactions of gases could occur outside of the jet which would result in a loss of efficiency for sample modification. As such, noble gases would not suffice for the transfer of energy to ambient air without diffusion away from samples being rectified. The gas temperature emanating from the nozzle of the PVA system is therefore higher. This will allow for an increase in activation of surfaces as the increased temperature agitates the molecules present and the bonds on the surface of the material, allowing for easier acceptance and functionalization at the surface boundary. From this and the addition of more directional and optimized transfer of energy due the internal chemical reactions, it can be assumed that the efficiency of the surface modification will increase. Therefore, from a technological viewpoint, a system that allows for chemical reactions to occur inside the system at the point of plasma discharge will give an increase in efficiency and better control of material modification. In this experiment, the PET samples that were treated became more hydrophilic with time, with the greatest change evident at a distance of $40 \mathrm{~mm}$ from the jet nozzle. It can be seen in Figs. 10 and 11 how WCA and SFE changes, respectively.

As an additional measurement, further analysis with EEDF ratios was carried out by obtaining OES data for 

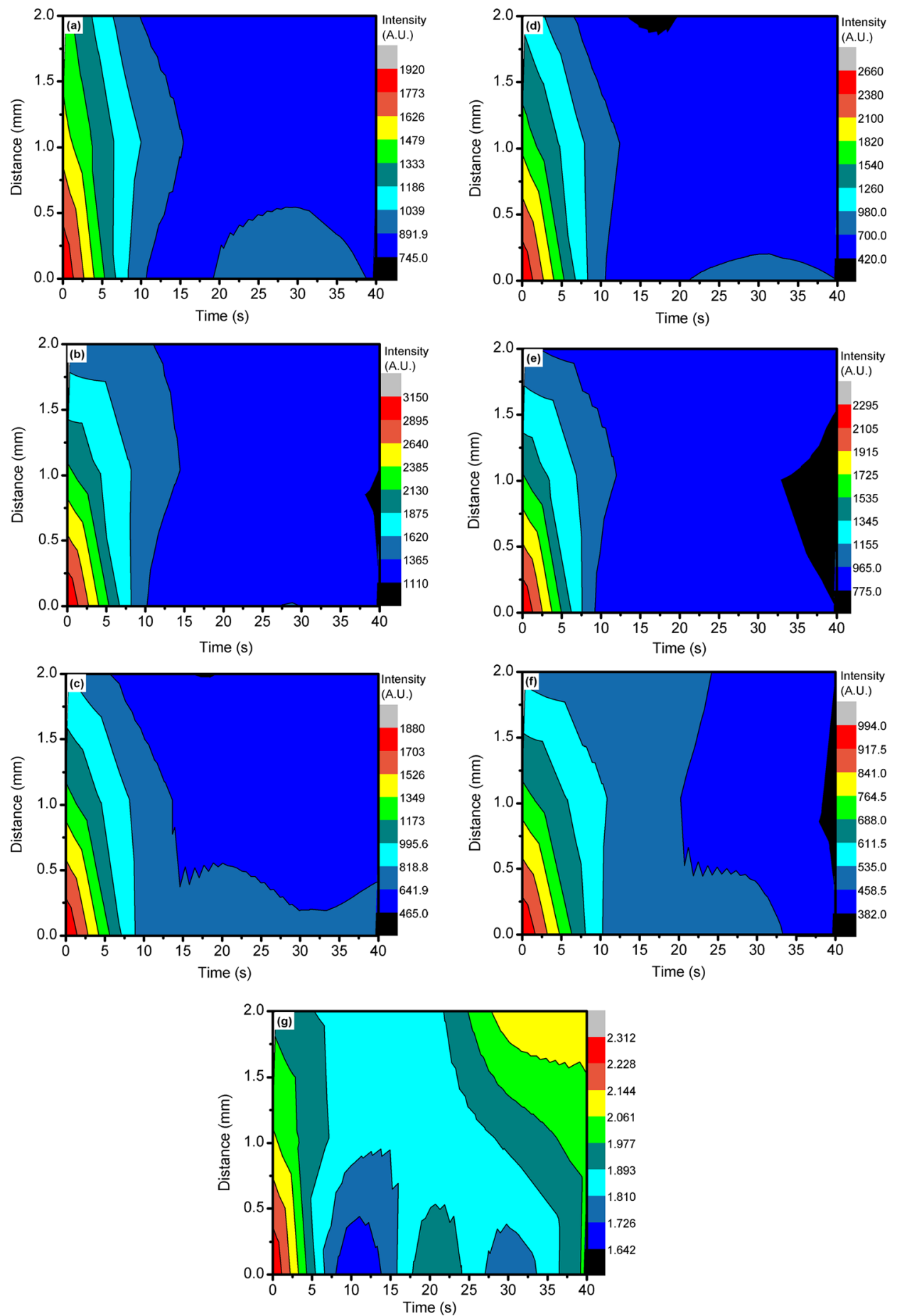

FIG. 9. (Color online) (a) Comparison of O I emissions in Ar over time and distance from the plasma nozzle. (b) Comparison of OH emission intensities over time and distance. (c) Graph of the emission of Ar at $750 \mathrm{~nm}$ (relevant for high energy electrons). (d) Graph of the spectral emissions of Ar at $811 \mathrm{~nm}$ (could be linked with metastable atom density). (e) and (f) Spectral emissions of $\mathrm{N}_{2}$ and $\mathrm{N}_{2}^{+}$molecules, respectively, over time and with varying distance. (g) Ratio of $\mathrm{N}_{2} / \mathrm{N}_{2}{ }^{+}$giving a shift in the EEDF with respect to time and distance.

Ar-750 and Ar-811 with an end-on view perspective. The EEDF was calculated by determining the ratio of Ar-811/Ar750. In Fig. 12, it can be seen that the EEDF ratio tends to increase with distance and varies very little over time.

\section{Discussion}

Figures 3(b) and 3(c) show how both $\mathrm{OH}$ and $\mathrm{NO}_{2}{ }^{*}$ decrease in intensity over time and distance. However, from 0 to $4 \mathrm{~mm}$, there is a dependence on time, and from $6 \mathrm{~mm}$ onward, a steady state appears for $\mathrm{OH}$ and $\mathrm{NO}_{2}{ }^{*}$. From this, it can be deduced that $\mathrm{OH}$ and $\mathrm{NO}_{2}{ }^{*}$ are dependent on each other throughout the course of the reactions, as proposed in mechanism (3) where $\mathrm{M}$ is $\mathrm{OH}$. As both of these decrease, $\mathrm{O}$ I is able to remain at a steady state from 2 to $6 \mathrm{~mm}$ from the jet nozzle, as shown in Fig. 3(a). This data show that although there are many reactive species created by the plasma 


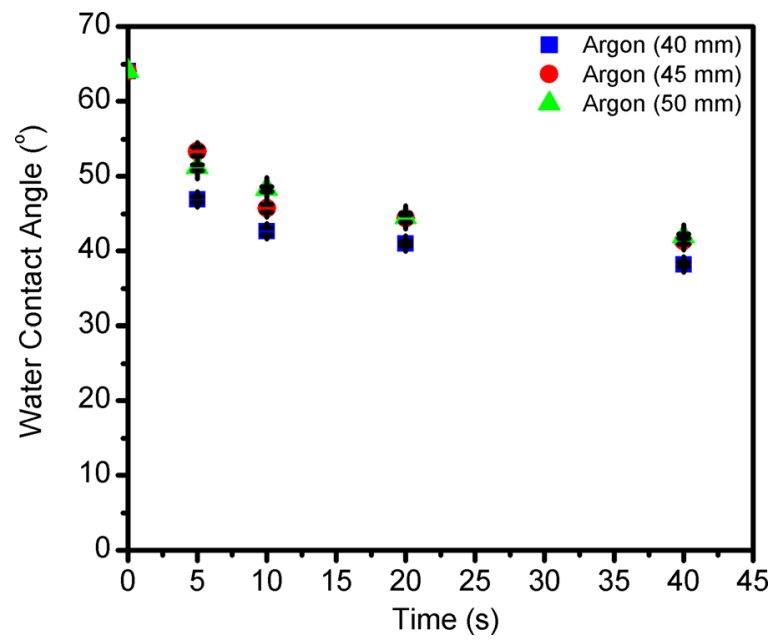

FIg. 10. (Color online) WCA values for PET samples treated with Ar.

discharge, in the case of air, the majority of the chemical reactions take place within the nozzle of the plasma jet and just at the exit. Further points from the nozzle have a more equalized and homogeneous state and can therefore create a more controllable activation and modification process for material surfaces. Looking at the intensity graphs of atomic oxygen (O I) emission for air and $\mathrm{CO}_{2}$ plasma discharge, it can be seen that the emission of $\mathrm{O} \mathrm{I}$ for air is a lot more consistent than $\mathrm{CO}_{2}$. The emission of $\mathrm{CO}_{2}$ undergoes a lot of fluctuation and can be reduced by up to $40 \%$ at times. From this, it is seen that for closer distances, the amount of $\mathrm{O} I$ generated by air will cause it to have more effect on the polymer surface over time.

For $\mathrm{CO}_{2}$, the emission of $\mathrm{O} \mathrm{I}$ is greatest in the region of the nozzle exit to $2 \mathrm{~mm}$ along the plasma plume. This can be seen in Fig. 6(a), which also shows that there are fluctuations that seem to repeat over a certain interval of time (i.e., 0,20 , and $40 \mathrm{~s}$ ) which gives evidence of the chemical reactions that arise within the gas over time. These fluctuations coincide with the changes seen in the $\mathrm{OH}$ and swan band emissions in Figs. 6(b) and 6(c). This shows that $\mathrm{OH}$ and the swan band emissions have a "relationship" with each other during the chemical reaction, which then gives rise to the observed emission spectra. The emission intensities seen in the swan band

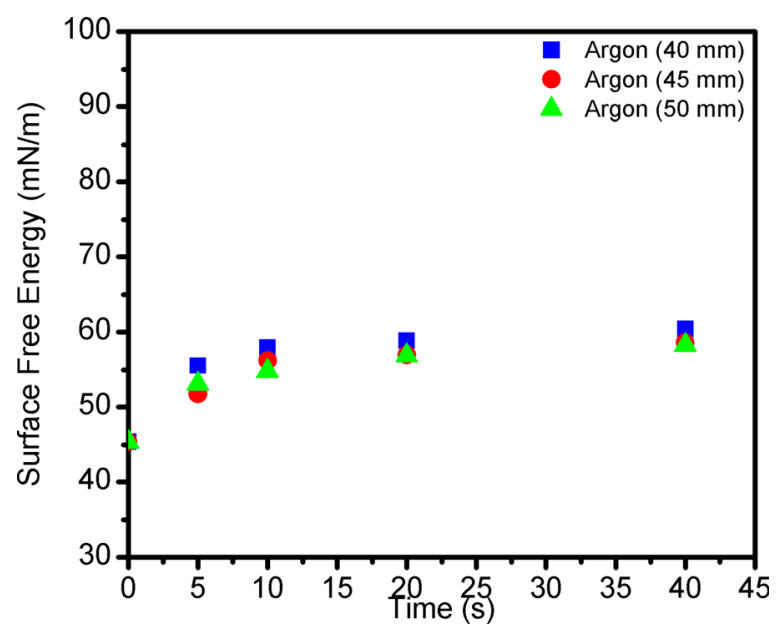

FIG. 11. (Color online) SFE values for PET samples treated with Ar.

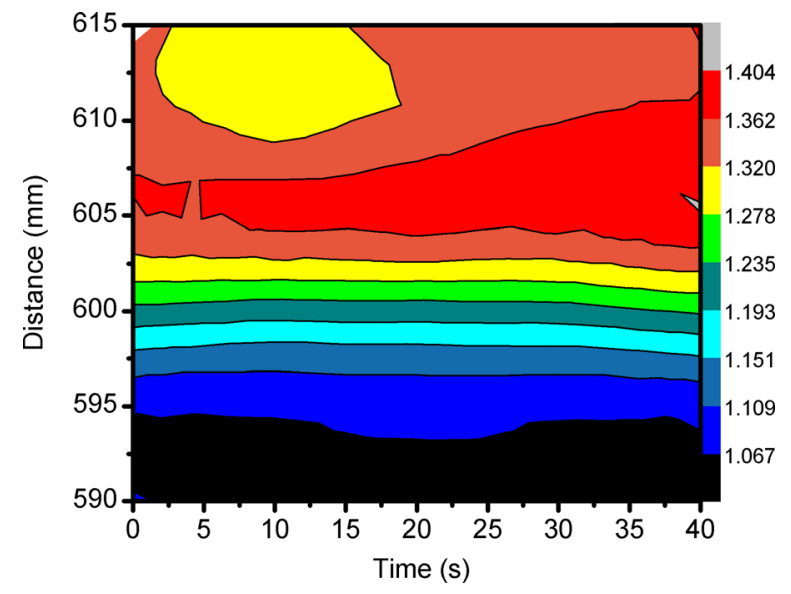

FIG. 12. (Color online) Ratio of Ar-811/Ar-750 giving a ratio change of the EEDF with respect to time and distance.

spectra are higher than those of the $\mathrm{OH}$ emissions, but changes in the intensity with respect to time and distance show a strong correlation between the changes in $\mathrm{OH}$ intensities over time and distance. This shows that there is a stoichiometric relationship between the $\mathrm{OH}$ species and the emitters of the swan band in $\mathrm{CO}_{2}$. However, these two decrease in intensity so does $\mathrm{O}$ I, which gains a more continuous emission over time. From these results, it can be deduced that due to the decreased interaction with $\mathrm{OH}$ and the swan band emitters, O I emission becomes more predictable. Therefore, the reactions for $\mathrm{CO}_{2}$ occur mainly within the nozzle or at the opening of the jet. Since the energy levels of $\mathrm{CO}_{2}$ (and its dissociation products) are in the range of up to $11 \mathrm{eV}$, they have similar energy levels to the chemistry of ambient air. In other words, $\mathrm{C}_{2}, \mathrm{CO}$, and $\mathrm{CO}^{+}$have similar energy levels to $\mathrm{N}_{2}$ and $\mathrm{O}$. This allows for a more efficient transfer of energy through radiative processes. So, at further distances from the polymer surface, $\mathrm{CO}_{2}$ could create more $\mathrm{O}$ I closer to the surface in comparison to that of air. This is due to a greater penetration through the ambient air due to a longer chain of radiative energy transfer between the $\mathrm{CO}_{2}$ discharge and the ambient air surrounding it.

All emission from the spectra obtained from the plasma discharge of Ar decrease in intensity with increasing distances along the plasma plume. Over the space of $10 \mathrm{~s}$, the intensities drastically drop for each species and then stay relatively constant for the remainder of the $40 \mathrm{~s}$. When comparing the emission of O I with Ar-750, it can be seen that these two have some form of interaction which is proposed by reaction (12). This allows us to see how much dependence the $\mathrm{O}$ I species have on $\mathrm{Ar}$ metastables as the requirement for energy transfer is essential. Another possibility of these reactions is the dependence of the Ar metastables on energized $\mathrm{N}_{2}$ through the mechanism shown previously (13). As $\mathrm{N}_{2}$ and $\mathrm{N}_{2}{ }^{+}$emission decrease, the level of Ar metastable emissions also decrease and consequently the amount of $\mathrm{O} I$ emissions. The EEDF ratios from $\mathrm{N}_{2} / \mathrm{N}_{2}{ }^{+}$appear to increase slightly after a drop between 10 and $20 \mathrm{~s}$. This is due to the $\mathrm{N}_{2}{ }^{+}$species decreasing more over time as the $\mathrm{N}_{2}$ species stay relatively constant after the initial drop after $10 \mathrm{~s}$ at the 
nozzle and then remain consistent at $2 \mathrm{~mm}$, due to the excited states energy difference.

The dependence of surface modification on the amount of O I available to react with and functionalize the surface has been shown. The treatment of the polymer surfaces at distances further away from the plasma source caused the surfaces to be less functionalized, which coincides with a decrease in the amount of $\mathrm{O}$ I. The use of air and $\mathrm{CO}_{2}$ gave similar results with respect to changes of WCA and SFE for the treated samples. This was expected as the total intensities of the atomic oxygen in air are close to $\mathrm{CO}_{2}$. Ar caused the least amount of change for the samples as the amount of atomic oxygen present was less than the other two; however, it did provide a more consistent change in WCA and SFE. From all of these results, it can be shown that the majority of reactions caused by the plasma discharge of the plasma jet system occur mostly within the nozzle of the jet or just outside the exit. For the majority of the reactive species, their intensities reduced quickly after $2 \mathrm{~mm}$ from the source and after which point the emitted light intensities were consistent over time.

\section{CONCLUSION}

After obtaining values for the emission intensities of $\mathrm{O} I$ and comparing them to the induced changes in WCA and SFE values of PET samples, this study found that there is proportionality between the modification of the polymer surface and the amount of reactive oxygen species produced. Other studies have shown that gases containing oxygen species cause a dual effect of etching and modification of bonds on polymer surfaces and that gases that contain active species of oxygen cause more of an effect through etching and forming polar groups. The results obtained from this study show an agreement with this. ${ }^{17-19,28,29}$ The levels of O I in $\mathrm{CO}_{2}$ and air were roughly the same with only slight variances over time. It was also found that the changes in WCA and SFE of samples treated with air and $\mathrm{CO}_{2}$ were close to each other. A dependence on the distance that the sample is from the plasma source was also observed. With the balance between thermal degradation and plasma interactions taken into consideration, the closer the sample is, the more changes its surface will undergo. With Ar, it can be seen that there is not as much of a change compared to $\mathrm{CO}_{2}$ and air for the induced changes in WCA and SFE with less fluctuations in $\mathrm{O}$ I over time. After calculating the EEDF for Ar, it was noted that the ratio increases with distance from the nozzle exit. From this observation, it can be concluded that the majority of the chemical reactions occur within the jet rather than externally in the surrounding ambient air. This is also confirmed by the end-on OES measurements of Ar. Consequently, the studied plasma jet creates a more efficient means to transfer energy to ambient air from the carrying gas. This can be seen in the shift of the EEDF further away from the nozzle point, showing that the bulk reactions happen internally. One of the reasons that could give rise to a difference between the proposed efficiency of this system compared to other systems that are used is their frequency of operation. Other factors that would also need to be considered include the power of the system, electrode geometry, and the system design. Examples would be the SurFX AtomFlo 400 system, which operates at $10-25 \mathrm{kHz}$, and the PlasmaStream ${ }^{\mathrm{TM}}$ system, which operates at $27.12 \mathrm{MHz}^{28,29}$ This can also be obtained from analyzing the data showing that the emissions of $\mathrm{OH}, \mathrm{NO}_{2}{ }^{*}$, and the swan bands in $\mathrm{CO}_{2}$ degrade and fluctuate with an increase in distance from the nozzle opening. However, the distance of the jet to the substrate surface is not the only factor that is important for polymer activation. The type of polymer used, gas chemistry, and treatment time are also factors that weigh in considerably.

\section{ACKNOWLEDGMENTS}

This work is a part of the Principle Investigation award funded by Scientific Foundation Ireland Plasma Grain project.

${ }^{1}$ S. K. Pankaj, C. Bueno-Ferrer, N. N. Misra, V. Milosavljević, C. P. O'Donnell, P. Bourke, K. M. Keener, and P. J. Cullen, Trends Food Sci. Technol. 35, 5 (2014).

${ }^{2}$ D. S. Trentin et al., Sci. Rep. 5, 8287 (2015).

${ }^{3}$ R. Wolf and A. C. Sparavigna, Engineering 2, 397 (2010).

${ }^{4}$ D. P. Dowling, J. Tynan, P. Ward, A. M. Hynes, P. J. Cullen, and G. Byrne, Int. J. Adhes. Adhes. 35, 1 (2012).

${ }^{5}$ M. Aliofkhazraei, Surface Energy, 1st ed. (InTech, Rijeka, Croatia, 2015), pp. 123-152.

${ }^{6}$ C. Mueller, G. Capaccio, A. Hiltner, and E. Baer, J. Appl. Polym. Sci. 70, 2021 (1998).

${ }^{7}$ M. Ozdemir, C. Yurteri, and H. Sadikoglu, Crit. Rev. Food Sci. Nutr. 39, 457 (1999).

${ }^{8}$ T. von Woedtke, S. Reuter, K. Masur, and K. D. Weltmann, Plasmas Med. Phys. Rep. 530, 291 (2013).

${ }^{9}$ D. S. Trentin et al., Surf. Coat. Technol. 245, 84 (2014).

${ }^{10}$ H. Yasuda, Radiat. Phys. Chem. 9, 805 (1977).

${ }^{11}$ S. Guruvenket, G. M. Rao, M. Komath, and A. M. Raichur, App. Surf. Sci. 236, 278 (2004).

${ }^{12}$ M. Lehocky, H. Drnovská, B. Lapciková, A. M. Barros-Timmons, T. Trindade, M. Zembala, and L. Lapcik, Jr., Colloids Surf. A 222, 125 (2003).

${ }^{13}$ M. Morra, E. Occhiello, and F. Garbassi, Surf. Interface Anal. 16, 412 (1990).

${ }^{14}$ A. Vesel and T. Semeni, Mater. Technol. 46, 227 (2012).

${ }^{15}$ J. M. Grace and L. J. Gerenser, J. Dispersion Sci. Technol. 24, 305 (2003).

${ }^{16}$ V. Milosavljevic, A. R. Ellingboe, and S. Daniels, Eur. Phys. J. D 64, 437 (2011).

${ }^{17}$ J. Wang, P. Chen, H. Li, L. Wei, B. Wang, C. Zhang, and N. Ren, Surf. Interface Anal. 40, 1299 (2008).

${ }^{18}$ P. Slepicka, N. Slepicková Kasálková, E. Stránská, L. Bacáková, and V. Švorcík, Express Polym. Lett. 7, 535 (2013).

${ }^{19}$ R. N. Wenzel, J. Phys. Chem. 53, 1466 (1949).

${ }^{20}$ NIST, "Atomic Spectra Database Lines (wavelength order)," http://physics.nist.gov, 2016.

${ }^{21}$ K. H. Becker, W. Groth, and D. Thran, Chem. Phys. Lett. 15, 215 (1972).

${ }^{22}$ R. L. Gattinger, W. F. J. Evans, I. McDade, D. A. Degenstein, and E. J. Llewellyn, Can. J. Phys. 87, 925 (2009).

${ }^{23}$ T. Sjimizu, Y. Sakiyama, D. B. Graves, J. L. Zimmermann, and G. E. Morfill, New J. Phys. 14, 103028 (2012).

${ }^{24}$ E. F. Mendez-Martinez, P. G. Reyes, D. Osorio-Gonzalez, F. Castillo, and H. Martinez, Plasma Sci. Technol. 12, 314 (2010).

${ }^{25}$ A. Schmidt-Bleker, J. Winter, A. Bösel, S. Reuter, and K. D. Weltmann, Plasma Sources Sci. Technol. 25, 015005 (2015).

${ }^{26}$ E. H. Lock, T. B. Petrova, G. M. Petrov, and S. G. Walton, Phys. Plasmas 23, 043518 (2016).

${ }^{27}$ M. Kuzuya, T. Izumi, Y. Sasai, and S. Kondo, Thin Solid Films 457, 12 (2004).

${ }^{28}$ M. Donegan, V. Milosavljević, and D. P. Dowling, Plasma Chem. Plasma Process. 33, 941 (2013).

${ }^{29}$ C. E. Nwankire, V. J. Law, A. Nindrayog, B. Twomey, K. Niemi, V. Milosavljević, W. G. Graham, and D. P. Dowling, Plasma Chem. Plasma Process. 30, 537 (2010). 